\title{
Total phenolic and flavonoid compounds, antioxidant and toxicity profile of extract and fractions of paku atai tuber (Angiopteris ferox Copel)
}

\author{
${ }^{1 *}$ Nur, S., ${ }^{1}$ Mubarak, F., ${ }^{1}$ Jannah, C., ${ }^{1}$ Winarni, D.A., ${ }^{2}$ Rahman, D.A., ${ }^{2}$ Hamdayani L.A. and \\ ${ }^{1}$ Sami, F.J. \\ ${ }^{1}$ Department of Pharmaceutical Chemistry, Sekolah Tinggi Ilmu Farmasi Makassar, Indonesia \\ ${ }^{2}$ Departement of Pharmaceutical Biology, Sekolah Tinggi Ilmu Farmasi Makassar, Indonesia
}

\begin{abstract}
Article history:
Received: 29 March 2019

Received in revised form: 18 May 2019

Accepted: 20 May 2019

Available Online: 3 June 2019
\end{abstract}

\section{Keywords:}

Paku atai tuber,

Phenolic,

Flavonoid,

$\mathrm{DPPH}$,

Reducing power,

BSLT

DOI:

https://doi.org/10.26656/fr.2017.3(6).135

\begin{abstract}
Paku atai plant (Angiopteris ferox Copel), specifically the tuber has been used empirically as an anticancer and antidote materials by Dayaknese in West Kutai, with limited scientific study. Thus, this research had been conducted to determine and evaluate the total phenolic, flavonoid content of this plant along with the antioxidant and toxicity profile. The research used several extracts' solvents including extraction with ethanol (crude extract, CE) and subsequently partitioned with n-hexane (HF); ethyl acetate (EF) and ethanol aqueous (EAF). The resulted crude extract and fractions were then analyzed through colorimetric method to determine the phenolic and flavonoid total; with DPPH and FRAP to observe the antioxidant activity; and using BSLT method to evaluate the toxicity activity. The results showed that the EF fraction provided the strongest antioxidant activity with $\mathrm{IC}_{50}$ value of $13.79 \mu \mathrm{g} / \mathrm{mL}$ and iron reduction with FRAP value of $387.5 \pm 6.41 \mu \mathrm{M} / \mathrm{g}$. However, a high correlation was observed between the antioxidant and the total phenolic content $\left(r^{2}=0.970-0.974\right)$ but little correlation in total flavonoid $\left(r^{2}=\right.$ 0.345 - 0.373). Furthermore, the EF (19.56 \pm 7.35$)$ showed the highest toxicity activity followed by CE $(22.42 \pm 2.10)$, HF $(39.52 \pm 7.38)$, and EAF (41.75 \pm 5.10$)$. Therefore, the paku atai tuber can be potentially developed as a natural antioxidant and anticancer material.
\end{abstract}

\section{Introductions}

The reactive oxygen species (ROS) form as products under normal physiological conditions due to the partial reduction of molecular oxygen. ROS are by-products of aerobic respiration involved in some modification of cellular reactions such as exposure to heavy metals, ionizing radiation and oxidant. Normally, ROS can be eliminated by the presence of endogenous antioxidant such as superoxide dismutase (SOD), catalase (CAT), glutathione peroxidase (GPx) and glutathione reductase (GR). However, the oxidative stress occurs when the balance between the oxidative and antioxidant in the body is changed by excess ROS production or insufficient of antioxidant defenses which causes cell damage and affects the body. To manage the process, the body's defense system will require external antioxidants (Cavas and Yurdakoc, 2005; Jia et al., 2014; Kim et al., 2016).

Antioxidants can neutralize free radicals by receiving or donating electrons; they will not turn into free radicals and remain stable. Antioxidants are effective to protect organisms against oxidative damages caused by ROS (Cho et al., 2011). Many antioxidants are found in vegetables, fruits and medicinal plants such as tocopherol, ascorbic acid, carotenoid, phenolic and flavonoid are good sources of antioxidants (Larson, 1988; Zerargui et al., 2016).

The increasing effects of damage in the body makes it necessary for the strategy of chemoprevention and the development therapeutics using natural ingredients such as plant extracts. Some plants have optimum characteristics of ROS level suppression and inhibition of the oxidation process that may significantly reduce the damage of cell structure in the body. The alleged mechanism occurs due to the presence of chemical compounds such as phenolic, and flavonoids that are responsible for protecting the body (Poulillot et al., 2011; Karim et al., 2014). Phenolic and flavonoid have a phenol ring with at least one hydroxyl substituent that enables inhibiting of ROS, reducing metal ions, modulating proteins phosphorylation related to inhibition of enzyme activity and inhibiting lipid peroxidation 
(Poulillot et al., 2011). Several studies have reported that the increasing dietary intake of natural antioxidants from plant may reduce coronary heart disease, cancer mortality and longer life expectancy (Halliwell, 2007; Rios et al., 2009).

Angiopteris ferox Copel or Indonesian namely "paku atai" is one of the ferns plants used as medicinal plants in Indonesia, that has the potential to develop as an antioxidant. In East Kalimantan, paku atai is empirically used as a drug as a breast anticancer and detoxification from the leaves, stems, sap and to its tubers. Fresh leaves, stems and tuber of paku atai are processed by boiling and drinking the water. The fresh tuber is shredded and mixed with rice flour then processed into powder, affixed to the affected body part. The sap from the tuber can be used directly by applying into the surface of the body's painful skin (Sundu et al., 2018).

Paku atai has been scientifically studied contain flavonoids, phenols, saponin, tannins and alkaloids (Sundu et al., 2018). However, the bioactivity studies of this plant compounds are still limited. Thus, this research had been conducted to study the antioxidant activity and toxicity of the extract and fractions of paku atai tuber, which can be useful in the anti-cancer research in the future.

\section{Materials and methods}

\subsection{Materials}

The reagents used were analytical grade 1,2-diphenyl -2-picrylhydrazyl (DPPH), ferrous sulfate, ferrous chloride, 2,4,6-tripyridyl-s-triazine, citric acid, quarcetine, ethanol, ethyl acetate, n-hexane, hydrochloric acid $(\mathrm{HCl})$, magnesium powder, Follin Ciocalteu, sodium acetate, aquabidestillata and Artemia salina Leach eggs.

\subsection{Sample preparation}

Paku atai (Angiopteris ferox Copel) tuber collected from East Kutai, Linggang Bigung District East Kalimantan and the classification (species) of paku atai plant was determined in Plant Anatomy and Systematic Laboratories, Mulawarman University Indonesia. The paku atai tuber was washed and air-dried at $50^{\circ} \mathrm{C}$ in the oven for 1-2 days until the weight was constant. Then, the sample was ground with a grinder. The grounded sample was extracted with ethanol $96 \%$ by maceration and then fractioned by liquid-liquid extraction. Briefly, each $500 \mathrm{~g}$ of sample was mixed with $2000 \mathrm{~mL} 96 \%$ (v/ v) ethanol and left overnight at room temperature. The supernatant of each sample was filtered with filter paper Whatman $(150 \mathrm{~mm})$ and the residue was re-macerated two times with $96 \%$ ethanol to achieve complete extraction. All extract was concentrated by a rotary evaporator at $50^{\circ} \mathrm{C}$ to obtain ethanol extract, namely crude extract (CE). The crude extract was then fractioned by liquid-liquid extraction. The extract was dissolved in ethanol-aqueous $(1: 10) \mathrm{v} / \mathrm{v}$ and dispensed into a separating funnel. The extract was also partitioned sequentially with n-hexane and ethyl acetate to obtain nhexane fraction (HF) and ethyl acetate fraction (EF) respectively. The resulting solvent fractions were concentrated using the rotary evaporator and dried in the vacuum oven at $30^{\circ} \mathrm{C}$. Then, the ethanol-aqueous fraction (EAF) was freeze-dried. The crude extract and the other solvent's fraction were stored in the dark at $4^{\circ}$ C.

\subsection{Determination of total flavonoid and phenolic content}

The total phenolic content in crude extract and various fractions were determined based on FolinCiocalteu method with slight modification (Singleton et al., 1999), while the flavonoid content was determined using $\mathrm{AlCl}_{3}$ colorimetric method with slight modification (Chang et al., 2002).

\subsection{Determination of antioxidant activities}

Antioxidant activity were evaluated using two different assay i.e. 1.2-diphenyl-2-picrylhydrazyl (DPPH), and Ferric Reducing Antioxidant Power (FRAP) which were adopted following the methods of Benzie and Strain, 1996, Karim et al. (2014), and Nur et al. (2017) with slight modifications.

\subsubsection{DPPH scavenging assay}

Briefly, $0.2 \mathrm{mM}$ DPPH solution and various concentration of the extracts and fractions (CE, HF, EF and EAF) with the serial dilution 1-1000 $\mu \mathrm{g} / \mathrm{mL}$ ) were prepared. Each sample was aliquoted into the flask and added with $1 \mathrm{~mL}$ of DPPH solution. The mixture was then diluted with ethanol to a total volume of $5 \mathrm{~mL}$ in the flask. The mixture was allowed to incubate for $30 \mathrm{mins}$ in the dark at room temperature before measuring its wavelength at $515 \mathrm{~nm}$. The scavenging effect was calculated based on the percentage of changing of the purple DPPH solution into yellow against the control (DPPH solution only without sample). The $\mathrm{IC}_{50}$ of the DPPH assay represents the concentration of the tested sample needed to reduce the DPPH by $50 \%$ where the value is obtained from linear regression graph (Karim et al., 2014). The percentage of inhibition value was calculated with the following formula:

$$
\% \text { Inhibition }=\frac{(\text { Abs blank }- \text { Abs sample })}{\text { Abs blank }} \times 100 \%
$$


Where Abs blank is the absorbance of the control and Abs sample is the absorbance of the sample. Quercetine was used as positive reference.

\subsubsection{Ferric reducing antioxidant power (FRAP) assay}

For FRAP assay, $500 \mu \mathrm{L}$ of the tested sample (CE, $\mathrm{HF}, \mathrm{EF}$ and $\mathrm{EAF}$ ) was added with $100 \mu \mathrm{L}$ ferric chloride solution ( $3 \mathrm{mM}$ in $5 \mathrm{mM}$ citric acid) and $2 \mathrm{~mL}$ TPTZ solution ( $1 \mathrm{mM}$ in $0.05 \mathrm{M}$ hydrochloric acid). The sample mixture was measured at the absorbance of 615 $\mathrm{nm}$ and the absorbance data was calculated against serial dilution of ferrous sulfate as standard curve $(16 ; 32 ; 64$; 128 ; and $254 \mu \mathrm{M})$ and recorded as equivalent to $\mu \mathrm{M}$ $\mathrm{Fe}^{2+}$. The FRAP value is the percentage of the reduction of $\mathrm{Fe}^{3+}$ to $\mathrm{Fe}^{2+}$ by the sample with $\mathrm{FeSO}_{4}$ expressed as $\mu \mathrm{M} / \mathrm{g}$ dry extract.

\subsection{Toxicity activity by brine shrimp lethality test (BSLT)}

Toxicity activity of extract and various fractions of paku atai tuber was carried out using BSLT method with slight modifications by Meyer et al. (1982). Firstly, Artemia salina Leach eggs were soaked in $50-100 \mathrm{mg}$ of seawater in an incubator for $48 \mathrm{hrs}$. The incubator was equipped with lights as a light source and was given an aerator that serves as oxygen supply and keeps the eggs from settling. The eggs were confirmed hatched and became larva. An amount of serial dilutions of extract and various fractions $(20,40,60,80$, and $100 \mu \mathrm{g} / \mathrm{mL})$ were prepared. About $10 \mathrm{~A}$. salina larvae aged $48 \mathrm{hrs}$ were randomly selected and transferred into the container. About $100 \mu \mathrm{L}$ of extract and various fractions dilution were added to the test container (triplicate treatment). Then, the solutions mixture was incubated for $24 \mathrm{hrs}$ at room temperature under illumination. The percentage of mortality of $A$. salina larvae in every concentration was counted and determined of $\mathrm{LC}_{50}$ value is the concentration that caused $50 \%$ of the death of larvae. The percentage of mortality value represented by the following equation:

$$
\% \text { mortality of larvae }=\frac{\sum \text { death of larvae }}{\sum \text { total larvae }} \times 100 \%
$$

\subsection{Statistical analysis}

Data analyses were performed using SPSS Statistic (21 version) software. Levels of significance were determined using one-way ANOVA followed by turkey test, where all samples of treatments were compared to the control. All data where expressed as mean \pm standard deviation and $\mathrm{p}$ values less than 0.05 were considered significantly different.

\section{Results and discussion}

The yield of the crude extract and fractions from paku atai are shown in the Table 1 . The yield of crude extract was $23.6 \%$ that indicated the raw material had a greater chance of being utilized. In fact, after fractionation process, $\mathrm{EF}$ had the highest yield at $37.1 \%$ followed by $\mathrm{HF}$ at $32.5 \%$ and EAF at $30.5 \%$. This could be due to the compounds contained in paku atai tuber extracts were more of semi-polar to non-polar. One of the factors that influenced the success of extraction was the selection of solvents. The selection of solvents is based on the principle 'like dissolves like' where a compound will dissolve in solvents that has the same polarity (Amaro et al., 2015).

Table 1. Yields $(\% \mathrm{w} / \mathrm{w})$ of the extract and fractions of paku atai tuber

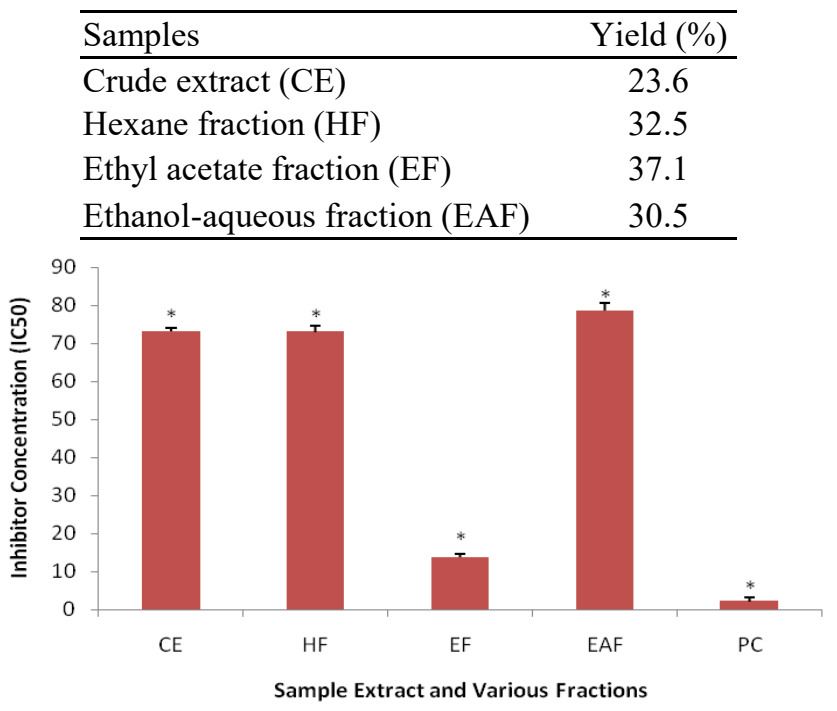

Figure 1. The $\mathrm{IC}_{50}$ value of crude extract and various fractions of Paku Atai Tuber by DPPH scavenging method. The measurement data was expressed by mean $\pm \mathrm{SD}(n=3)$. Quercetine was used as positive control (PC) for DPPH scavenging method. *Shows significant differences between samples and positive control $(\mathrm{p} \leq 0.05)$.

The antioxidant activity of the crude extract and fractions of the paku atai tuber was analyzed using two tests which were DPPH radical scavenging and reduction of iron (FRAP) test. DPPH has been extensively used as a free radical to evaluate the antioxidant substances present in the crude extract and fractions that will reduce DPPH by donating hydrogen to form the non-radical DPPH (Kedare and Singh, 2011). The results in Figure 1 showed that EF provided a strongest antioxidant activity compared to the others with $\mathrm{IC}_{50}$ values of $13.79 \mu \mathrm{g} / \mathrm{mL}$ followed by CE $(72.3 \mu \mathrm{g} / \mathrm{mL}), \mathrm{HF}(73.01 \mu \mathrm{g} / \mathrm{mL})$, and EAF $(78.6 \mu \mathrm{g} / \mathrm{mL})$. These results suggested that compounds with the strongest antioxidant capacity to reduce DPPH may be more soluble in a semi polar solvent such as ethyl acetate. However, other solvents from polar to less polar such as ethanol-aqueous and nhexane may provide the antioxidant capacity to reduce 

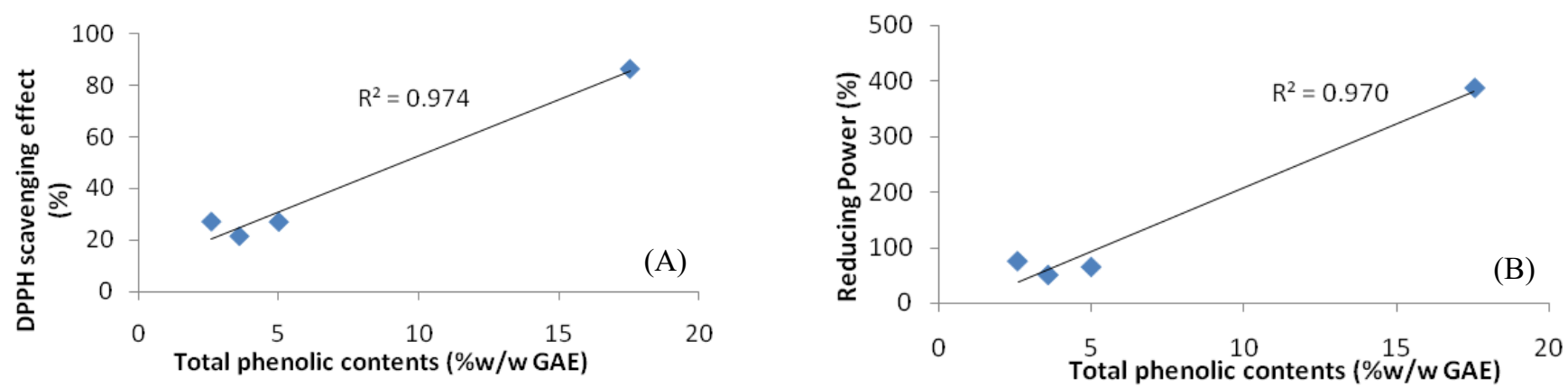

Figure 2. The correlation between total phenolic contents (x-axis) with antioxidant activities (y-axis) of the the extract and fractions of paku atai tuber. (A) DPPH scavenging activities and (B) reducing power by FRAP.

DPPH radical. Generally, the DPPH scavenging activity of EF was comparable with quercetine as the positive control, a natural antioxidant flavonoid derivate with $\mathrm{IC}_{50}$ value $2.18 \mu \mathrm{g} / \mathrm{mL}$ (strongest antioxidant).

As for FRAP assay, the sample should be able to provide antioxidants activity based on the Fenton reaction mechanism by chelating metal ions such as $\mathrm{Fe}^{2+}$ and $\mathrm{Cu}^{2+}$ responsible to convert hydrogen peroxide into radicals hydroxyl occur into the body (Apak et al., 2007). The results (Table 2) showed that EF (387.5 \pm 6.41 $\mu \mathrm{M} / \mathrm{g}$ ) had a significantly higher antioxidant activity than the HF $(74.85 \pm 6.63 \mu \mathrm{M} / \mathrm{g}), \mathrm{CE}(64.36 \pm 2.95 \mu \mathrm{M} / \mathrm{g})$ and EAF $(49.95 \pm 1.96 \mu \mathrm{M} / \mathrm{g})$. Nevertheless, the paku atai tuber extract and fractions still provided a good antioxidant activity. A high antioxidant capacity is indicated by the high FRAP value. It can be noted that the compounds fractioned in the EF of the paku atai tuber are group of flavonoids or phenolics that contributed to the mechanism chelating metal ions and reduce the possibility of the formation of hydroxyl

Table 2. Ferric reduction power of the extract and fractions of paku atai tuber by FRAP assay

\begin{tabular}{lc}
\hline \multicolumn{1}{c}{ Samples } & $\begin{array}{c}\text { Reduction Power } \\
(\mu \mathrm{M} / \mathrm{g} \text { sample } \pm \mathrm{SD})\end{array}$ \\
\hline Crude extract (CE) & $64.36 \pm 2.95^{*}$ \\
Hexane fraction (HF) & $74.85 \pm 6.63^{*}$ \\
Ethyl acetate fraction (EF) & $387.5 \pm 6.41^{*}$ \\
Ethanol-aqueous fraction (EAF) & $49.95 \pm 1.96^{*}$ \\
Positive Control (PC) & $526.23 \pm 3.06^{*}$ \\
\hline
\end{tabular}

Values are expressed as mean $\pm \mathrm{SD}(\mathrm{n}=3)$. Quercetine was used as positive control (PC) for reduction power assay. *Significant different between the samples and the positive control $(\mathrm{p} \leq 0.05)$.

radicals are derived from the anion superoxide radical (Kulisic et al., 2004; Lim et al., 2007). This also showed that the ethyl acetate was more efficient to partition antioxidant compounds in paku atai tuber than other solvents.

The total phenolic and flavonoid content may be correlated with their antioxidant capacity of the extract and solvent partitioned fraction types of paku atai tuber (Ganesan et al., 2008). Table 3 shows that the total phenolic and flavonoid contents of the extract and fractions. Based on the results, the total phenolic contents obtained was in the range from 2.58 to $17.55 \%$ GAE (w/w) and the total flavonoid content obtained was in the range from 0.07 to $0.14 \% \mathrm{QE}(\mathrm{w} / \mathrm{w})$. Among the extract and fractions, EF had significantly higher levels of total phenolic and flavonoid contents, $17.55 \% \mathrm{GAE}$ and $0.14 \%$ QE respectively which could have a correlation with the antioxidant activity (Ye et al., 2009). $\mathrm{HF}$ and EAF had significantly lower levels than EF.

The phenolic and flavonoid contents of the extract and fractions have a role in increasing its antioxidant activity, both in DPPH radical capture and iron reduction power activity by FRAP testing. The correlation between the amounts of phenolic and flavonoid contents of the extract and fractions against the antioxidant capacity can be seen in Figure 2. Based on Figure 2(A), it was shown that the relationship between total phenolic contents with the antioxidant activity in reducing radical DPPH had a correlation coefficient of 0.974 . This indicated that the contribution of phenolic in extract and various fractions of antioxidant activity were affected by $97.4 \%$ while $2.6 \%$ of antioxidant activity was influenced by the contribution of other non-phenolic compounds. The same trend was observed in reducing power activity with a correlation coefficient of 0.970 where $97 \%$ of antioxidant activity to reduce $\mathrm{Fe}^{3+}$ to $\mathrm{Fe}^{2+}$ was influenced by phenolic compounds while the $3 \%$ was influenced by non-phenolic compounds. In this data, it can be estimated that the phenolic contents of samples were correlates directly with antioxidant activity.

Minimal correlation was observed between the total flavonoids and antioxidant activity for DPPH scavenging in Figure 3(A) $\left(r^{2}=0.345\right)$ and for reducing power in Figure $3(B)\left(r^{2}=0.373\right)$ of the extract and fractions. It can be interpreted that $34.5 \%$ and $37.3 \%$ of total flavonoids in the extract and fractions gave contributions as antioxidant to DPPH radical scavenging and reducing power respectively. In this case, flavonoid compounds of extract and various fractions of paku atai tuber may not be directly correlated with their antioxidant activities.

BSLT is a very easy, inexpensive method for toxicity 
Table 3. Total phenolic and flavonoid content of the extract and fractions of paku atai tuber

\begin{tabular}{lcc}
\hline \multicolumn{1}{c}{ Samples } & Total Phenolic $(\% \mathrm{w} / \mathrm{w}$ GAE) & Total Flavonoid (\%w/w QE) \\
\hline Crude extract (CE) & $4.996 \pm 0.440^{\mathrm{bcd}}$ & $0.126 \pm 0.005^{\mathrm{cd}}$ \\
Hexane fraction (HF) & $2.580 \pm 0.113^{\mathrm{acd}}$ & $0.127 \pm 0.002^{\mathrm{cd}}$ \\
Ethyl acetate fraction (EF) & $17.55 \pm 0.953^{\mathrm{abd}}$ & $0.14 \pm 0.0006^{\mathrm{abd}}$ \\
Ethanol-aqueous fraction (EAF) & $3.586 \pm 0.272^{\mathrm{abc}}$ & $0.077 \pm 0.006^{\mathrm{abc}}$ \\
\hline
\end{tabular}

Values are expressed as mean \pm SD $(n=3)$. Different alphabet superscripts in the same column indicate significant difference $(\mathrm{p} \leq 0.05)$.
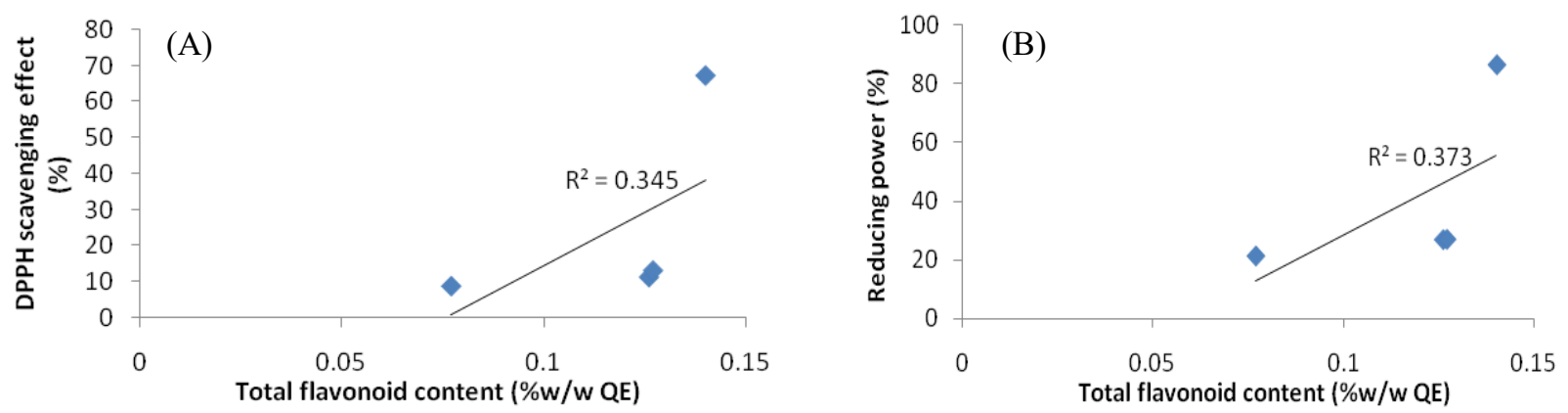

Figure 3. The correlation between total flavonoids content (x-axis) with antioxidant activities (y-axis) of the extract and fractions of paku atai tuber. (A) DPPH scavenging activities and (B) reducing power by FRAP method.

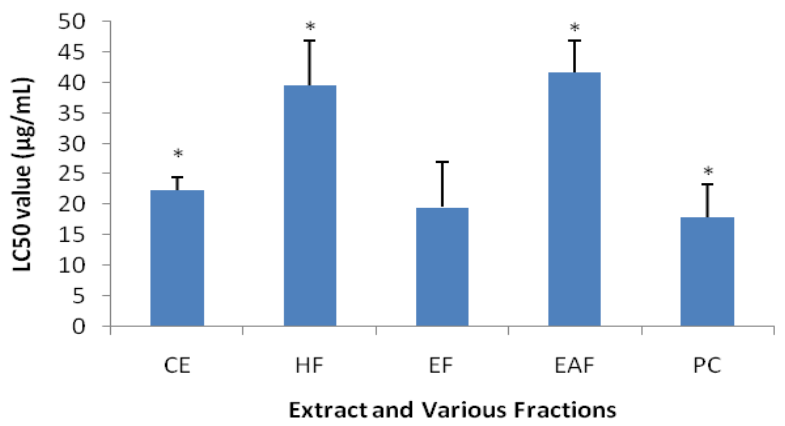

Figure 4. The $\mathrm{LC}_{50}$ value of crude extract and various fractions of Paku Atai Tuber were conducted by BSLT method. The measurement data were expressed by mean $\pm \mathrm{SD}$ $(\mathrm{n}=3)$. Quercetine was used as positive control (PC) for BSLT method. *Shows significant differences between samples and positive control $(\mathrm{p} \leq 0.05)$.

testing that strongly supports initial screening to determine the effects of chemical compounds as anticancer. The chemical compound is assumed less toxic if the $\mathrm{LC}_{50}$ value observed is less than $1000 \mu \mathrm{g} / \mathrm{mL}$ and highly toxic if $\mathrm{LC}_{50}$ value is less than $30 \mu \mathrm{g} / \mathrm{mL}$. In this study, 48-hour-old larvae were used because at that age the organs of $A$. salina larvae were fully formed (Meyer et al., 1982). The $\mathrm{LC}_{50}$ value of extract and various fractions are shown in Figure 4. Based on the result in Figure 4, the extract and fractions had a toxic effect of $A$. salina larvae at $\mathrm{LC}_{50}$ value less than $100 \mu \mathrm{g} / \mathrm{mL}$ (Nguta et al., 2012). The EF gives the highest toxic effect characterized by a low $\mathrm{LC}_{50}$ value $(19.55 \pm 7.34)$ followed by CE (22.42 \pm 2.09$)$, HF $(39.51 \pm 7.38)$, and EAF (41.74 \pm 5.09$)$. The $\mathrm{LC}_{50}$ value of $\mathrm{EF}$ was almost the same as the $\mathrm{LC}_{50}$ value of the positive control (17.89 \pm 5.48$)$. The mechanism of larval death is estimated to be related to the presence of flavonoid compounds in the extract and fractions that inhibit the feeding power of larvae. These compounds act as a stomach poison which disrupt their digestive organs. In addition, these compounds inhibit the taste receptors of the larvae which causes the larvae to fail to recognize food and die of starvation (de Padua et al., 1999; Agustini, 2017). Based on the results of the toxicity assay, the paku atai tuber can be developed as anti-cancer.

\section{Conclusion}

This research demonstrated that the extract and fractions from paku atai tuber had significant antioxidant activity with the EF having the highest DPPH radical scavenging $\left(\mathrm{IC}_{50}\right.$ value of $13.79 \mu \mathrm{g} / \mathrm{mL}$ ) and reducing power based on the FRAP assay $(387.5 \pm 6.41 \mu \mathrm{M} / \mathrm{g})$. A high correlation was observed between the antioxidant activity and the phenolics content $\left(\mathrm{r}^{2}=0.970-0.974\right)$ but minimal correlation was observed between the antioxidant activity and the flavonoids content $\left(\mathrm{r}^{2}=\right.$ $0.345-0.373$ ). For toxicity study, EF had the highest toxicity with $\mathrm{LC}_{50}$ value of $19.56 \pm 7.35$. This study implied that the EF of paku atai tuber can be considered to be developed as a natural antioxidant and anticancer agent.

\section{Acknowledgements}

The authors were grateful to research center (Lembaga Penelitian dan Pengabdian Masyarakat) STIFA Makassar and Al Marisah Madani Foundation for founding this research as well as Dr. Nursamsiar from STIFA Makassar who has helped reviews this article.

\section{References}

Agustini, N.W.S. (2017). Identification of Active Compound and Biological Toxicity of Extract of n- 
Hexane, Ethyl Acetate and Ethanol From Microalgae Tetraselmis chuii with Brine Shrimp Lethality Test (BSLT). Warta IHP/Journal of Agro-based Industry, 34(1), 8-17. https://doi.org/10.32765/ wartaihp.v34i1.4063

Amaro, H.M., Fernandes, F., Valentão, P., Andrade, P.B., Sousa-Pinto I., Malcata, F.X. and Guedes, A.C. (2015). Effect of Solvent System on Extractability of Lipidic Components of Scenedesmus obliquus (M21) and Gloeothece sp. on Antioxidant Scavenging Capacity Thereof. Marine Drugs, 13(10), 64536471. https://doi.org/10.3390/md13106453

Apak, R., Güçlü, K., Demirata, B., Özyürek, M., Çelik, S., Bektaşoğlu, B., Berker, K. and Özyurt, D. (2007). Comparative Evaluation of Various Total Antioxidant Capacity Assays Applied to Phenolic Compounds with the CUPRAC Assay. Molecules, 12(7), 1496-1547. https://doi.org/10.3390/12071496

Benzie, I.F.F. and Strain, J.J. (1996) The Ferric Reducing Ability of Plasma (FRAP) as a Measure of "Antioxidant Power": The FRAP Assay. Analytical Biochemistry, 239(1), 70-76. https://doi.org/10.1006/ abio.1996.0292

Cavas, L. and Yurdakoc, K. (2005). An investigation on the antioxidant status of the invasive alga Caulerpa racemosa var cylindracea (Sonder) Verlaque, Huisman, et Boudoresque (Caulerpales, Chlorophyta), Journal of Experimental Marine Biology and Ecology, 325(2), 189-200. https:// doi.org/10.1016/j.jembe.2005.05.002

Chang, C.C., Yang, M.H., Wen, H.M. and Chern, J.C. (2002). Estimation of Total Flavonoid Content in Propolis by Two Complementary Colorimetric Methods. Journal of Food and Drug Analysis, 10(3), 178-182.

Cho, M., Lee, H.-S., Kang, I.-J., Won, M.-H. and You, S. (2011). Antioxidant properties of extract and fractions from Enteromorpha prolifera, a type of green seaweed. Food Chemistry, 127(3), 999-1006. https://doi.org/10.1016/j.foodchem.2011.01.072

de Padua, L.S., Bunyapraphatsara, N. and Lemmens, R.H.M.J. (1999). Plant Resources of South-East Asia No 12 (1/2): Medicinal and poisonous plants. Leiden, Netherlands: Backhuys Publishers.

Ganesan, P., Kumar, C.S. and Bhaskar, N. (2008). Antioxidant properties of methanol extract and its solvent fractions obtained from selected Indian red seaweeds. Bioresource Technology, 99(8), 27172723. https://doi.org/10.1016/j.biortech.2007.07.005

Halliwell, B. (2007). Dietary polyphenols: Good, bad, or indifferent for your health?. Cardiovascular Research, 73(2), 341-347. https://doi.org/10.1016/ j.cardiores.2006.10.004

Jia, N., Li T., Diao, X. and Kong, B. (2014). Protective effects of black currant (Ribes nigrum L.) extract on hydrogen peroxide-induced damage in lung fibroblast MRC-5 cells in relation to the antioxidant activity. Journal of Functional Foods, 11, 142-151. https://doi.org/10.1016/j.jff.2014.09.011

Karim, A.A., Azlan, A., Ismail, A., Hashim, P., Abd Gani, S.S., Zainudin, B.H. and Abdullah, N.A. (2014). Phenolic composition, antioxidant, antiwrinkles and tyrosinase inhibitory activities of cocoa pod extract. BMC Complementary and Alternative Medicine, 14, 381. https://doi.org/10.1186/14726882-14-381

Kedare, S.B. and Singh, R.P. (2011). Genesis and development of DPPH method of antioxidant assay. Journal of Food Science and Technology, 48(4), 412 -422. https://doi.org/10.1007/s13197-011-0251-1

Kim, D.-B., Shin, G.-H., Kim, J.-M., Kim, Y.-H., Lee, J. -H., Lee, J.S., Song, H.-J., Choe, S.Y., Park, I.-J., Cho, J.-H. and Lee, O.-H. (2016). Antioxidant and anti-ageing activities of citrus-based juice mixture. Food Chemistry, 194, 920-927. https:// doi.org/10.1016/j.foodchem.2015.08.094

Kulisic, T., Radonic, A., Katalinic, V. and Milos, M. (2004). Use of different methods for testing antioxidative activity of oregano essential oil. Food Chemistry, 85(4), 633-640. https://doi.org/10.1016/ j.foodchem.2003.07.024

Larson, R.A. (1988). The antioxidants of higher plants. Phytochemistry, 27(4), 969-978. https:// doi.org/10.1016/0031-9422(88)80254-1

Lim, Y.Y., Lim, T.T. and Tee, J.J. (2007). Antioxidant properties of several tropical fruits: A comparative study. Food Chemistry, 103(3), 1003-1008. https:// doi.org/10.1016/j.foodchem.2006.08.038

Meyer, B.N., Ferrigni, N.R., Putnam, J.E., Jacobsen, L.B., Nichols, D., Nicols, L. and McLaughlin, J. (1982). Brine Shrimp: A Convenient General Bioassay for Active Plant Constituents. Journal of Medicinal Plant Research. Planta Medica, 45(5), 3134. https://doi.org/10.1055/s-2007-971236

Nguta, J., Mbaria, J., Gakuya, D., Gathumbi, P., Kabasa, J. and Kiama, S. (2012). Evaluation of Acute Toxicity of Crude Plant Extracts from Kenyan Biodiversity using Brine Shrimp, Artemia salina L. (Artemiidae). The Open Conference Proceedings Journal, 3, 30-34. https:// doi.org/10.2174/2210289201203010030

Nur, S., Rumiyati, R. and Lukitaningsih, E. (2017). Screening of antioxidants, anti-aging and tyrosinase inhibitory activities of ethanolic and ethyl acetate 
extracts of fruit flesh and fruit peel langsat (Lansium Domesticum Corr) in vitro. Traditional Medicine Journal, 22(1), 63-72. https://doi.org/10.22146/ tradmedj.24342

Poulillot, A., Polla, L.L., Tacchini, P., Neequaye, A., Polla, A. and Polla, B. (2011). Natural Antioxidants and their Effects on the Skin. In Dayan, N. and Kromidas, L. (Eds.). Formulating, Packaging, and Marketing of Natural Cosmetic Products. p. 239-257. USA: John Wiley and Sons, Inc. https:// doi.org/10.1002/9781118056806.ch13

Rios, A.D.O., Antunes, L.M.G. and Bianchi, M.D.L.P. (2009). Bixin and lycopene modulation of free radical generation induced by cisplatin-DNA interaction. Food Chemistry, 113(4), 1113-1118. https://doi.org/10.1016/j.foodchem.2008.08.084

Singleton, V.L., Orthofer, R. and Lamuela-Raventós, R.M. (1999). Analysis of total phenols and other oxidation substrates and antioxidants by means of folin-ciocalteu reagent. In Packer, L. (Ed.) Methods in Enzymology, p. 152-178. USA: Academic Press. https://doi.org/10.1016/S0076-6879(99)99017-1

Sundu, R., Handayani, F., Sapri, S. and Nurhasnawati, H. (2018). Uji Aktivitas Antioksidan Fraksi N-Heksan, Kloroform Dan Etil Asetat Dari Ekstrak Etanol Umbi Paku Atai Merah (Angiopteris ferox Copel). Jurnal Ilmiah Ibnu Sina, 3(2), 261-265.

Ye, H., Zhou, C., Sun, Y., Zhang, X., Liu J., Hu, Q. and Zeng, X. (2009). Antioxidant activities in vitro of ethanol extract from brown seaweed Sargassum pallidum. European Food Research and Technology, 230(1), 101-109. https://doi.org/10.1007/s00217-009 $-1147-4$

Zerargui, F., Baghiani, A., Khennouf, S. and Arrar, L. (2016). Antioxidant activity assessment of Tamus communis L. Roots. International Journal of Pharmacy and Pharmaceutical Sciences, 8(12), 6471. https://doi.org/10.1007/s00217-009-1147-4 